\title{
ASSESSMENT OF VOLUME AND ABOVE-GROUND BIOMASS IN ARAUCARIA FOREST THROUGH SATELLITE IMAGES, COMPARING DIFFERENT METHODS IN THE SOUTH OF CHILE
}

\author{
F. Pirotti ${ }^{1,2, *}$, E. Kutchartt ${ }^{1}$, E. Csaplovics ${ }^{3}$ \\ ${ }^{1}$ TESAF Department, University of Padova, Via dell’Università 16, 35020 Legnaro (PD) Italy - francesco.pirotti@ unipd.it \\ ericokutchartt@gmail.com \\ ${ }^{2}$ CIRGEO, Interdepartmental Research Center of Geomatics, University of Padova, Via dell’Università 16, 35020 Legnaro (PD) \\ ${ }^{3}$ Institute of Photogrammetry and Remote Sensing, Faculty of Environmental Sciences. Technische Universität Dresden. \\ elmar.csaplovics@tu-dresden.de
}

Commission III, WG III/10

KEY WORDS: Above-ground forest biomass, Remote Sensing, SAR backscatter, Landsat, wavelets

\begin{abstract}
:
Initial results of biomass estimation in the La Fusta area from existing equations found in literature are presented. As expected, accuracy of general equations suffer from the equation coefficients being obtained from fitting training data from different sites. It is also clear from the results that there is a high variance between different methods, in particular when complex data mixture is applied. Biomass is difficult to assess for dense forests, as pixels are saturated. This must be considered when planning field-data collection, with more samples in dense forest to provide more robust estimators from the training phase. The SAR-only (PALSAR) method from eq. 4 provided the most bias in results, overestimating with respect to the other methods.
\end{abstract}

\section{INTRODUCTION}

Understanding the distribution and dynamics over time of tree biomass distribution is a key topic for understanding and monitoring forest ecosystems. Forest carbon stock represents an important component of the total biomass and can be grouped by the following sub-components: below ground, above ground, and the latter further into trunk, leaves, branches. Ground sampling is the most accurate way to measure biomass (Segura and Kanninen, 2005), in particular when allometric equations are available in a specific site. Unfortunately ground measurements are a time-consuming and expensive process, in particular in areas that are difficult to access (Vaglio Laurin et al., 2016; Wang et al., 2011). It remains clear that in-situ sampling is the only way to train a model. The sampling strategy can be optimized through initial rough estimation of biomass through remote sensing. These downsides of ground-sampling have led to a wide interest in the use of remote sensing data for estimating forest characteristics, from tree height distribution to more detailed vertical structure information. Fields of applications are also numerous, ranging from global biomass maps to more detailed hazard maps related to dead-wood, important for example for estimating fire hazard (Jucker et al., 2017; Marchi et al., 2018).

Remote sensing is a term that aggregates a wide array of sensors that provide data. Active and passive remote sensing are differentiated from emitting or not emitting the electromagnetic energy (EME) that is then recorded; both types are useful for analysis of vegetation, in agriculture and forestry (Koch, 2010). Also, different range capabilities distinguish sensors; from UAVs to platform orbiting $\sim 700-1000$ kilometres from the Earth surface. The geospatial aspect is embedded in remote sensing, as accurate geolocation of data is of paramount importance. A lot of scientific effort has been dedicated to finding new and improved ways to get better understanding of forest characteristics using all types of remote sensing data. Figure 1 shows a survey over the past 10 years on scientific literature using the key phrase "forest volume and biomass estimation using remote sensing" as opposed to only searching for "remote sensing" in Google Scholar. It shows that a relative significant increase is evident in the past 10 years of activities using remote sensing for estimation of biomass and volume.

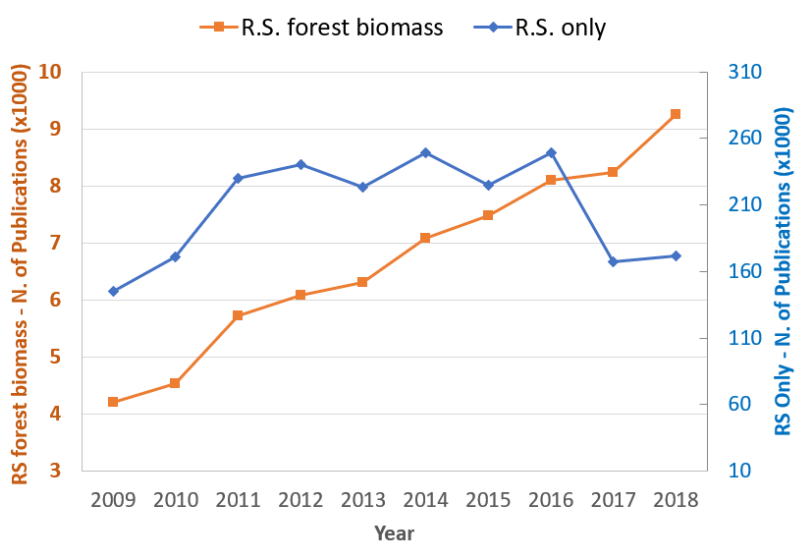

Figure 1. Google Scholar literature search for keywords "forest volume and biomass estimation using remote sensing" (orange) and "remote sensing" only (blue).

Technology has greatly improved the spatial and radiometric resolution of satellite imagery. The past years have seen a fast development of many methods for applying passive and active

Corresponding author 
satellite imagery as source of information in the field of forest measurements. Higher resolution imagery improved the quality of several vegetation indices that can estimate values of some forest stand attributes such as basal area, volume and above ground biomass. Forest structure impacts on the reflectivity of the incident EME from the sun or from the active sensor, and this information is recorded and available in the image. Specifically height and crown cover are highly correlated with biomass (Lefsky et al., 1999; Yáñez et al., 2008) and both spectral signatures and backscatter intensities change from a bare-ground area to a dense tropical forest. One of the main challenges in based on remote sensing for biomass estimation is overcoming the saturation effect, i.e. predictions of small biomass changes at low biomass values are more accurate than at high biomass values. This is true for methods using optical properties and backscatter properties, i.e. optical remote sensing and SAR (Ulaby et al., 1984). Therefore, it must be taken in consideration that predicted values are less reliable when estimating higher biomass values.

The presented research compares results from using various existing and new approaches for biomass estimation using imagery with different resolutions, including open and commercial imagery (e.g., Sentinel-2A, Landsat-8, QuickBird, etc.). The focus is to define the impact of resolution over the estimation of the forest stand attributes in Araucaria forest type, as a pilot study area. Accurate allometric equations are used to estimate volume and above ground biomass from ground samples. A non-linear model with more than one covariate is used to provide detailed biomass values by tree components (e.g., wood, foliage, etc).

Initial investigation regarding the assessment of biomass over the study area is performed. At this stage ground-data is not yet available, so the focus of results is on comparing different methods that are available in existing literature for estimating biomass in similar ecosystems. We start enumerating the methods and sensors that are tested, with a critical discussion on differences found in results. The natural continuation of this work will be training stage of a model using ground-data acquired insitu.

Field data providing tree position, diameter, height and crown volume are used for training, testing and validation phases. The allometric equation that will be used on to estimate above ground biomass in the field-samples with Araucaria araucana shows a strong relationship, obtaining a $\mathrm{R}^{2}$ of 0.99 and a relative root mean square error (rRMSE) of $13.8 \%$ and a bias of $0.5 \%$ (journal publication with further details is currently under review), thus is considered suitable for training and validation of the prediction models. At the final stages this study will use both direct band reflectance and band transformations such as spectral indices such are NDVI, SAVI and DVI. These will be combined with forest inventory data, using relationships between forest structural variables and vegetation indices to provide an accurate prediction.

At this stage data from field sampling are not yet available, therefore comparisons are carried out over biomass maps derived from existing equations found in literature. In this comparison both optical and radar datasets are used, separated or also mixed in a single model. More details are provided in the methods sections.

\section{MATERIALS AND METHODS}

\subsection{Study area}

The study area is located at La Fusta forest, region of the Araucania in the south of Chile (38 $34^{\prime} 28^{\prime \prime}$ S and $71^{\circ} 26^{\prime} 22^{\prime}$ ' $\mathrm{W}$ ), covering a total area of $\sim 9000$ ha and divided in 981 stands (see Figure 2). The terrain is characterized by low altitudinal variation, between 1,290 and 1,380 meters. The mean annual precipitation of this location varies from 1,500 to $2,500 \mathrm{~mm}$, with temperatures from $-1^{\circ} \mathrm{C}$ to $9^{\circ} \mathrm{C}$ (Hajek and Rubio, 1982). The soils were composed under volcanic rocks, being soils moderately deep with a medium to fine texture in deep, showing a moderate to high erodibility, acid $\mathrm{pH}$ and low nutritional level (Donoso, 2006). The area is mainly dominated by Araucaria araucana, but commonly is associated to Nothofagus spp. in low zones. Especially, with Lenga (Nothofagus pumilio) as is well described by Schmidt, (1977)

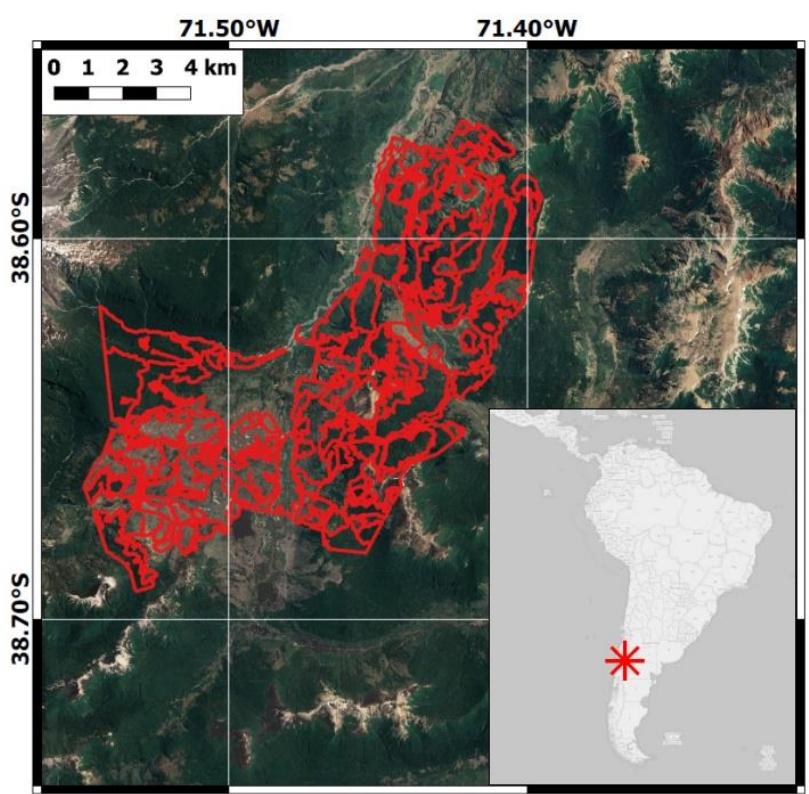

Figure 2. Study area, La Fusta, Chile.

\subsection{Materials}

Data from multiple active and passive remote sensors were used for application of existing equations in literature for assessing biomass. Google Earth Engine (GEE) was used as data provider and partially for some procedures. Google Earth Engine provides remote computing capabilities over remote sensing data collections. Processing is done through mapping pre-defined and user-defined functions for data analysis and aggregating results through aggregating operators called "reducers"(Gorelick et al., 2017). For this initial comparative analysis these satellite missions are used: Landsat 5/7/8, Sentinel-2 and PALSAR. Because vegetation has a natural seasonal variation, image collections were filtered to use only months with highest vegetation photosynthetic activity. In this area in the southern hemisphere the time window from January to end of March provide warmest days with low precipitation, and therefore it was used to keep a low seasonal variation regarding vegetation response to certain EME wavelengths, such as the red-edge area of spectrum. Pre-processing steps and details on work-flow are provided in the next sections. 


\subsection{Methods}

A lot of investigation has been done in the past 30 year by the scientific community for finding best methods for forest volume and biomass estimation using different sources of remote sensing technologies; optical passive sensor data, Synthetic Aperture Radar (SAR) and lidar. Several authors have provided summary of state-of-the-art on remote sensing-based aboveground biomass estimation methods in forest ecosystems (Koch, 2010; Lu et al., 2016). Biomass estimation techniques using remote sensing data can use either parametric and nonparametric approaches. Parametric models assume that the relationships between dependent (i.e. biomass) and independent (derived from remote sensing data) variables have explicit model structures that can be specified a priori by parameters (Lu et al., 2016). In this study ground measurements are not yet available; therefore, no training data is yet available for testing non-parametric algorithms. Instead parametric methods with parameters defined in literature from studies in similar contexts can be tested to compare different sensors and different time windows. Therefore, based on previous literature, the methods presented in the next sections are used and results compared in the discussion sections.

2.3.1 Optical sensor data: the most common data available from satellite missions is passive optical sensor data providing visible, near infrared and short-wave infrared radiance/reflectance information. Numerous satellite missions provide open-data, which is an important paradigm for fostering a rich environment in scientific collaboration (Pirotti, 2019).

Early work from (Steininger, 2000) found a correlation value of $R=0.8 p<0.01$ using Landsat TM channel 5 atmospherically corrected reflectance values to estimate biomass over stands in Brazil's secondary tropical forest up to $15.0 \mathrm{~kg} \cdot \mathrm{m}^{-2}$. Saturation effects were present above that amount of dry biomass.

$$
\begin{array}{r}
\text { AGB }=50.77-287.62 \cdot \mathrm{X} \\
\text { AGB }=4.166 \mathrm{e}+5 \mathrm{e}^{-73.936 \cdot X}
\end{array}
$$

where: $\mathrm{AGB}=$ above-ground biomass $\left(\mathrm{kg}^{\cdot} \mathrm{m}^{-2}\right), \mathrm{X}=$ Landsat $\mathrm{TM}$ channel 5 atmospherically corrected reflectance and $\mathrm{e}=$ natural logarithm. In our study-case the corresponding bands in Landsat 5, 7 and 8 have been used, to provide a timeline of biomass values over the La Fusta area.

Methods based on band transformations and indices have been used for predicting biomass of vegetation. The red-edge area in the EME spectrum is sensible to photosynthetic activity, as chlorophyll absorbs the red EME and healthy vegetation strongly reflects near infrared (NIR). Therefore, NDVI and other red-edge indices are strongly correlated to the photosynthetic activity and are thus a proxy of vegetation-fraction in a mixed pixel. A drawback is that equations relating NDVI to biomass are very robust at low values of biomass, and get saturated as biomass increases (van der Meer et al., 2000).

2.3.2 Synthetic Aperture Radar - SAR: biomass models based on using SAR data have been tested in both agriculture and forestry. SAR is an active remote sensing technology which emits signals in the microwave part of the energy spectrum. Reflected signal contains phase and amplitude information that can be analysed for relation with biomass. Amplitude is recorded as backscatter magnitude value commonly expressed in decibels (dB) after applying the following conversion:

$$
D N(d B)=10 \cdot \log _{10}(D N)-\mathrm{CF}
$$

where DN is the recorded backscatter at the sensor after processing the raw signal to sigma naught and/or gamma naught and $\mathrm{CF}$ is a calibration factor. Sigma naught $\sigma_{0}$ is the backscattered portion of the incident energy on the illuminated area, gamma naught $\left(\gamma_{0}\right)$ is the backscatter portion of the area defined to be in the plane perpendicular to the line of sight from sensor to an ellipsoidal model of the ground surface (Small, 2011). Depending on the wavelength of the emitted signal, SAR missions are put in categories defined by a letter (see Figure 3).

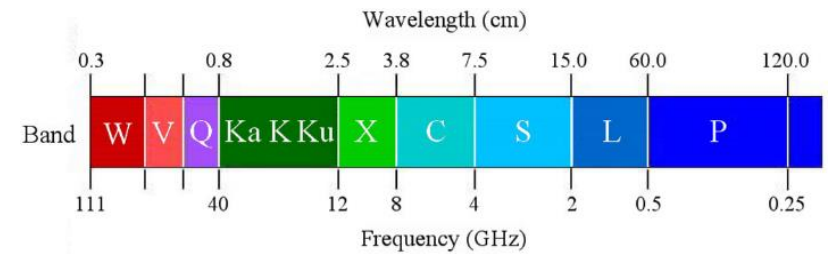

Figure 3. Radar band designations relative to emitted wavelength (image credit https://www.sweclockers.com/artikel/21125kommunikation-i-rymden/6 ).

Earth surface objects interact with radar emitted energy backscattering the signal with an intensity that depends on the wavelength and on the surface characteristics. The surface characteristics include geometry of the surface (incidence angle), texture, and surface properties, such as dielectric properties, material and water content (Wohlfart et al., 2018). In the case of vegetation, longer wavelengths have a greater degree of canopy penetration. Shorter SAR wavelengths such as X-band and C-band interact mainly with the top part of the canopy while long wavelengths such as L-band have a greater penetration depth, interacting with the entire canopy (Jiao et al., 2010; Ulaby et al., 1984).

In this work a test was done using the $\mathrm{HH}$ and $\mathrm{HV}$ polarizations of the following radar sensors available in GEE:

- Sentinel-1 C-band radar with $10 \mathrm{~m}$ spatial resolution;

- PALSAR/PALSAR-2 L-band radar with $25 \mathrm{~m}$ spatial resolution

For both sensors the following pre-processing steps were carried out by the provider, GEE: radiometric calibration and terrain correction using SRTM 30 m digital elevation model. Sentinel-1 also had thermal noise removed. PALSAR also had de-striping according to method in (Shimada, 2010). It must be noted that Sentinel-1 data are provided as sigma naught, whereas PALSAR are provided as gamma naught.

SAR backscatter is weakly correlated with biomass, and is therefore used mainly to improve models that use optical information (Basuki et al., 2013). Equations that use mixed models are discussed in the next section. A SAR-only approach, the Water Cloud model (Attema and Ulaby, 1978; Ulaby et al., 1984) was tested successfully in (Peregon and Yamagata, 2013) and is tested here as well:

$$
\mathrm{AGB}=\frac{1}{0.03} \cdot \ln \left(\frac{\sigma_{0}+12.6}{-10.119}\right)
$$

$\mathrm{AGB}=$ above-ground biomass $\left(\mathrm{Mg}^{\cdot} \mathrm{ha}^{-1}\right)$.

2.3.3 Mixed: using SAR and optical sources of data can improve biomass models. Fusion implies different sources of data such as: (i) SAR backscatter, (ii) SAR coherence, (iii) 
reflectance from optical sensors, (iv) derived vegetation indices, and (v) texture maps through Grey Level Co-occurrence Measures GLCM (Haralick, 1979) of optical or SAR backscatter values. These features have been tested for improvement of predictions of above-ground biomass models by (Basuki et al., 2013; Vaglio Laurin et al., 2016) and others. Authors in Vaglio Laurin et al. (2016) used SAR backscatter intensity from ALOS2, NDVI values from Landsat-8 and GLCM maps finding that the best model was obtained using both SAR and NDVI $\left(\mathrm{R}^{2}=0.66\right.$, RMSE $=7.162 \mathrm{~kg}^{\cdot} \mathrm{m}^{-2}$ ). In their work GLCM values did not help to predict variance in above-ground biomass. Saturation of the model occurs approximately over $35 \mathrm{~kg} \cdot \mathrm{m}^{-2}$

$$
\mathrm{AGB}=4.53+16 \cdot \mathrm{HH} . \mathrm{HV}+10.03 \cdot \mathrm{NDVI}
$$

where: $\mathrm{AGB}=$ above-ground biomass $\left(\mathrm{Mg}^{-} \mathrm{ha}^{-1}\right)$, HH.HV is the sum of backscatter values (in $\mathrm{dB}$ ), and NDVI is the average NDVI over a $5 \times 5$ window.

In other tests, GLSM values have proven to be a valid support to biomass prediction, providing equations with significant correlation. A coefficient of determination $\mathrm{R}^{2}=0.84$ was the result of the work by Gascón and Eva, (2014) using high resolution imagery (around $1 \mathrm{~m} \times 1 \mathrm{~m}$ cell size) with the following relation:

$$
\begin{aligned}
\mathrm{AGB}= & -179+70.5 \cdot \mathrm{GLCM} H 45+3.201 \cdot \mathrm{GLCMSD} 2 \\
& -0.012 \cdot \text { Mean } 4+59.01 \cdot \mathrm{NDVI}
\end{aligned}
$$

Where GLCM SD2 is the standard deviation of band 2, GLCM GLCM H45 is the GLCM Homogeneity at $45^{\circ}$, Mean4 is the GLCM mean of band 4 and NDVI is the Normalized Difference Vegetation Index.Another mixed approach is presented by Basuki et al. (2013) with results providing a coefficient of determination $\mathrm{R}^{2}=0.746$ and an RMSE of $7.89 \mathrm{~kg} \cdot \mathrm{m}^{-2}$ with the following equation:

$$
\mathrm{AGB}=-83.304+1073.298^{\circ} \cdot v e g \_h h-1436.975 \cdot \text { soil_hh }
$$

where: AGB is above-ground biomass $\left(\mathrm{Mg}^{\cdot} \mathrm{ha}^{-1}\right)$, veg_hh and soil_hh are respectively the $\mathrm{HH}$ polarization mixed with the vegetation and soil fractions calculated using endmembers of the respective components. Endmembers were derived by defining in the image a pure pixel for each component, vegetation and soil. Authors in (Basuki et al., 2013) inject SAR's HH backscatter and fractional reflectance using discrete wavelet transformation (DWT). Authors do not provide information on what software/library was used for DWT and only indicate a generic orthogonal wavelet transform, but do not specify which from the possible orthogonal wavelet filters (e.g. Haar, Daubechies, Binomial QMF). In this presented study steps (i) spectral unmixing to endmembers "soil" and "vegetation" and (ii) DWT steps were done respectively by using GRASS GIS's i.spec.unmix package (Tonolli et al., 2011) and R-cran waveslim package (Mallat, 1989; Whitcher, 2019). Reconstruction of the optical fraction of soil and vegetation with injection of PALSAR's HH backscatter using the inverse transform with DWT was done with the following weighted model as indicated in Basuki et al. (2013):

$$
C_{\text {opt }}^{Z}=a_{o p t}^{Z} \cdot C_{P A L S A R}^{Z}+b_{P A L S A R}^{Z}
$$

where $Z=$ three directions, horizontal, vertical and diagonal Wavelet detail image directions; $a_{o p t}^{Z}$ is the mean of the optical remotely sensed data, $b_{P A L S A R}^{Z}$ is the standard deviation of the PALSAR data.

\section{RESULTS AND DISCUSSION}

From the methods described in the previous sections, five equations for estimating biomass are finally applied to the La Fusta area: equation 1, 4, 5, 6 and 7. The first is based on a single reflectance band, the short-wave infrared band at $1.55-1.75 \mu \mathrm{m}$ wavelength range. The others use SAR backscatter only or mix GLMC and a mixed combination of SAR and optical band transformations, either with spectral indices and with endmember fractions.

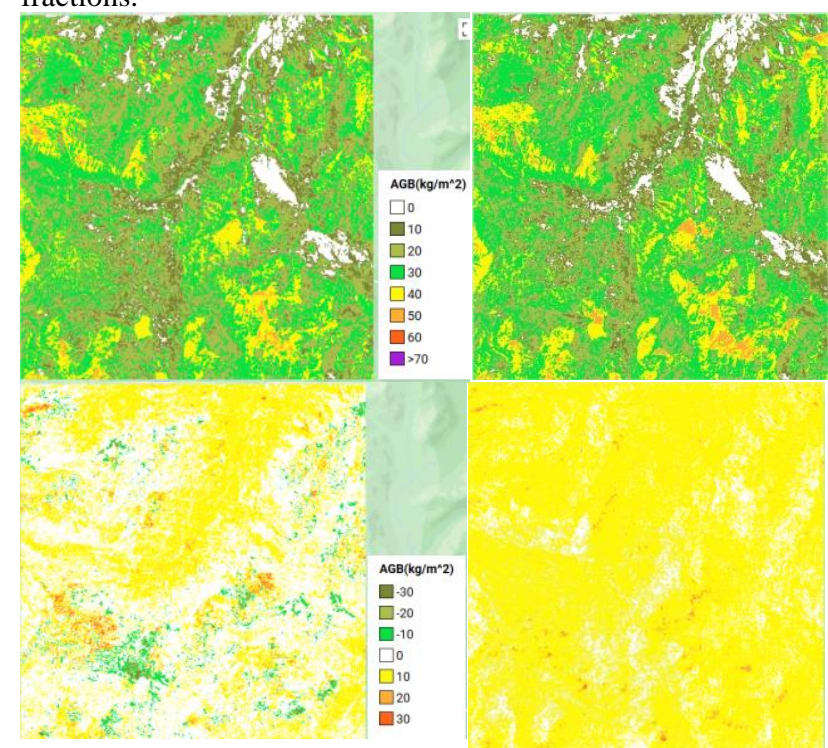

Figure 4. La Fusta area in 2002 - above-ground biomass estimated using eq. 1 with Landsat 7 ETM+ (top left) and Landsat 5 TM (top right) and difference map from single year (bottom left) and from composite (bottom right).

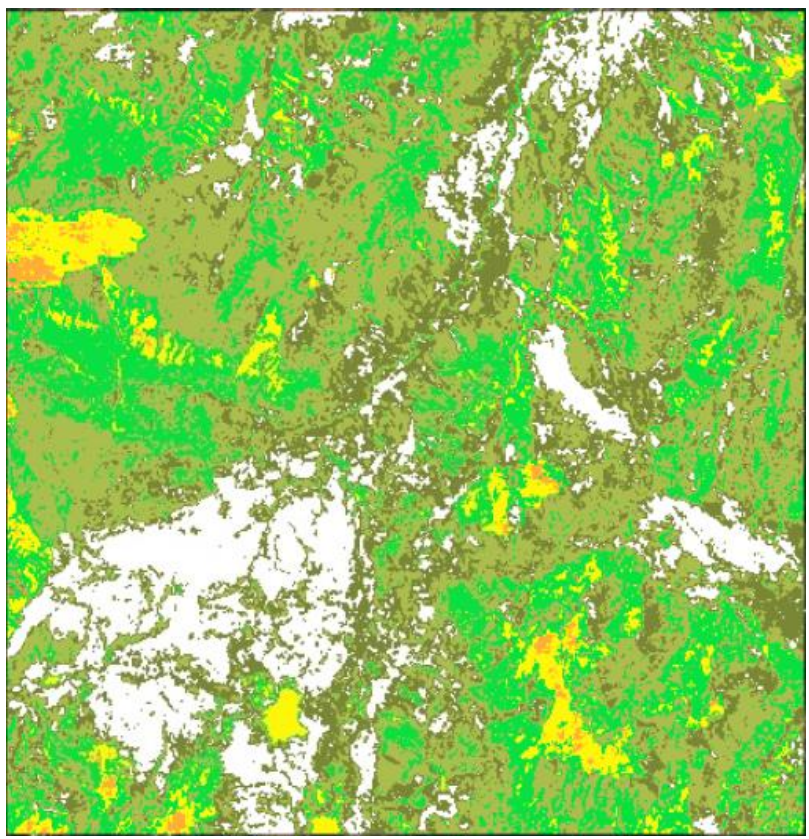

Figure 5. Model from eq. 1 applied using Landsat-8 and PALSAR/PALSAR-2 - area without vegetation at bottom left is in-line with lost vegetation checked with global forest change in (Hansen et al., 2013). 

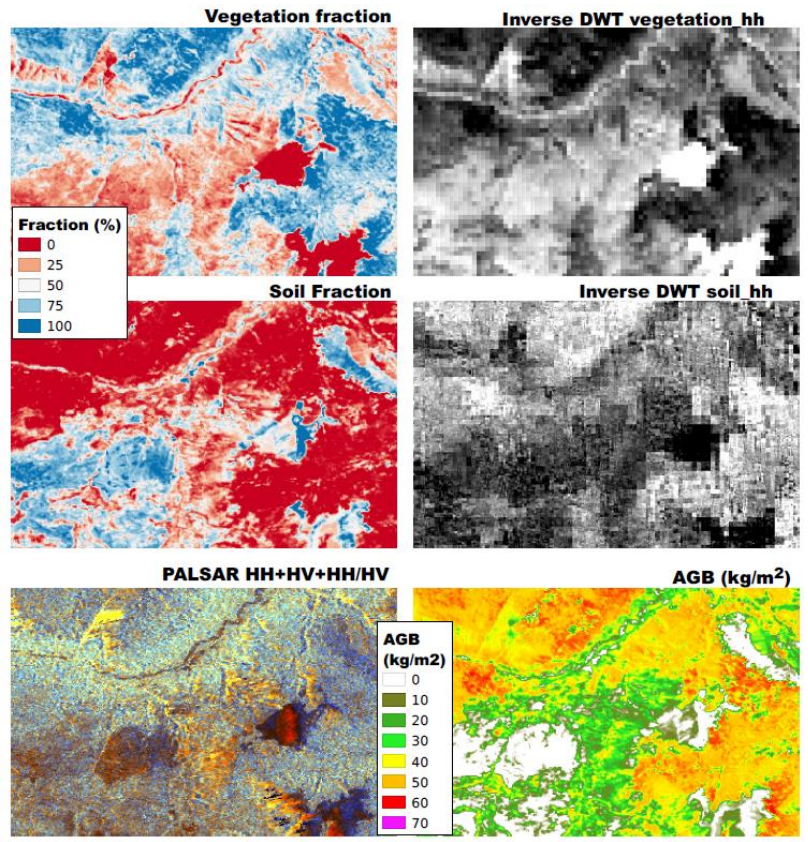

Figure 6. Intermediate and final results from application of mixing optical and SAR data with wavelet as in (Basuki et al., 2013).

A critical comparison between the results can provide initial information on the area and on criticalities of the methods. The difference maps can be used to map higher ground sample density in future sampling planning. A first exploratory analysis can be done comparing histograms of frequency distribution of biomass values over all the area (Figure 7).
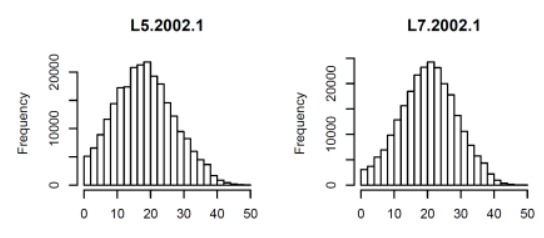

$\checkmark$
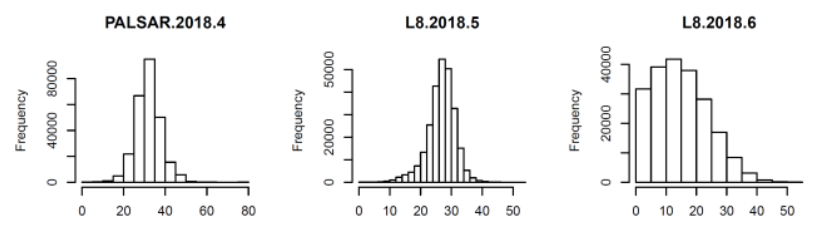

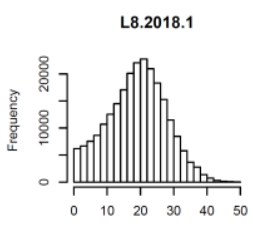

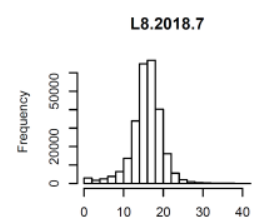

Figure 7. Histogram of biomass estimated values (v) in $\mathrm{kg}^{\cdot} \mathrm{m}^{-2}$ with different methods: title shows sensor, year and equation used.

\subsection{Multi-temporal comparison}

Due to the long-term Landsat missions, equation 1 was applied to Landsat 5, 7 and 8, the first two in 2002 the latter in 2018. Landsat 7 had a failure in 2003 of its scan line corrector in the ETM+ sensor, therefore earlier dates that were analysed.
It is worth noting that testing on a composite over a single season (2002) as opposed to a larger composite over three years (2000 to 2002), respectively and 26 Landsat-5 images and 40 Landsat7 images, using the median surface reflectance values, provided a much more robust result as seen in the image below. It is trivial to say that taking a first moment statistic (mean or median) will smooth results and therefore obviously decrease differences, but it must be said that the objective of this test is to see behaviour of two sensors, TM and ETM+ over the same time window and that first moment statistics will remove random errors (white noise), but will still be sensible to systematic errors.

Parcels used for management are used here for aggregating biomass data at parcel level and analyse results from the different methods. Six of the largest areas are used to provide quantiles and represent them in boxplot (Figure 8).

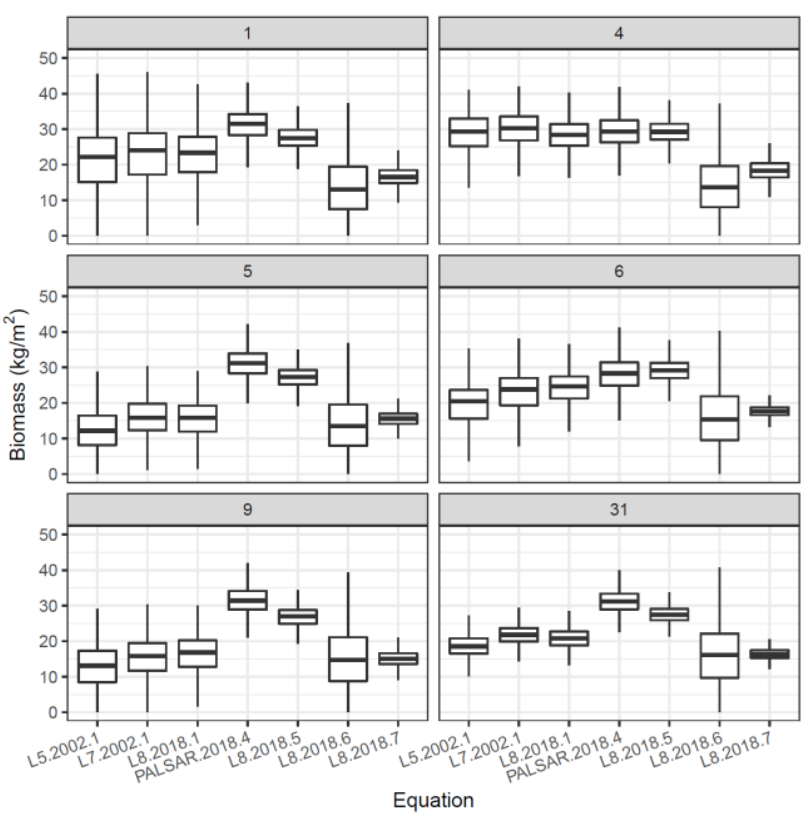

Figure 8. Aggregated statistics for six parcels.

\section{CONCLUSIONS}

Several equations for estimating biomass using optical and SAR remote sensing are tested and results are presented in this paper. As expected, general equations suffer from the equation coefficients being obtained from fitting training data from different sites. It is also clear from the results that there is a high variance between different methods, in particular when complex data mixture is applied. Biomass is difficult to assess for dense forests, as pixels are saturated. This must be considered when planning field-data collection, with more samples in dense forest to provide more robust estimators from the training phase. The SAR-only (PALSAR) method from eq. 4 provided results which appear more biased, overestimating with respect to the other methods.

\section{REFERENCES}

Attema, E.P.W., Ulaby, F.T., 1978. Vegetation modeled as a water cloud. Radio Sci. https://doi.org/10.1029/RS013i002p00357 
Basuki, T.M., Skidmore, A.K., Hussin, Y.A., van Duren, I., 2013. Estimating tropical forest biomass more accurately by integrating ALOS PALSAR and Landsat-7 ETM+ data. Int. J. Remote Sens. https://doi.org/10.1080/01431161.2013.777486

Donoso, C., 2006. Las especies arbóreas de los bosques templados de Chile y Argentina. Autoecología, Las especies arbóreas de los bosques templados de Chile y Argentina. Autoecología.

Gascón, L.H., Eva, H., 2014. Field guide for forest mapping with high resolution satellite data. https://doi.org/10.2788/657954

Gorelick, N., Hancher, M., Dixon, M., Ilyushchenko, S., Thau, D., Moore, R., 2017. Google Earth Engine: Planetary-scale geospatial analysis for everyone. Remote Sens. Environ. https://doi.org/10.1016/j.rse.2017.06.031

Hajek, E.R., Rubio, P., 1982. Bioclimatología de montaña en Chile. II. Entalpía del aire. Rev. Med. Chil.

Hansen, M.C., Potapov, P. V., Moore, R., Hancher, M., Turubanova, S.A., Tyukavina, A., Thau, D., Stehman, S. V., Goetz, S.J., Loveland, T.R., Kommareddy, A., Egorov, A., Chini, L., Justice, C.O., Townshend, J.R.G., 2013. High-Resolution Global Maps of 21st-Century Forest Cover Change. Science (80. ). 342, 850-853. https://doi.org/10.1126/science.1244693

Haralick, R.M., 1979. Statistical and structural approaches to texture. Proc. IEEE. https://doi.org/10.1109/PROC.1979.11328

Jiao, X., McNairn, H., Shang, J., Liu, J., 2010. The sensitivity of multi-frequency ( $\mathrm{X}, \mathrm{C}$ and L-band) radar backscatter signatures to bio-physical variables (LAI) over corn and soybean fields, in: International Archives of the Photogrammetry, Remote Sensing and Spatial Information Sciences - ISPRS Archives.

Jucker, T., Caspersen, J., Chave, J., Antin, C., Barbier, N., Bongers, F., Dalponte, M., van Ewijk, K.Y., Forrester, D.I., Haeni, M., Higgins, S.I., Holdaway, R.J., Iida, Y., Lorimer, C., Marshall, P.L., Momo, S., Moncrieff, G.R., Ploton, P., Poorter, L., Rahman, K.A., Schlund, M., Sonké, B., Sterck, F.J., Trugman, A.T., Usoltsev, V.A., Vanderwel, M.C., Waldner, P., Wedeux, B.M.M., Wirth, C., Wöll, H., Woods, M., Xiang, W., Zimmermann, N.E., Coomes, D.A., 2017. Allometric equations for integrating remote sensing imagery into forest monitoring programmes. Glob. Chang. Biol. 23, 177-190.

Koch, B., 2010. Status and future of laser scanning, synthetic aperture radar and hyperspectral remote sensing data for forest biomass assessment. ISPRS J. Photogramm. Remote Sens. 65, 581-590. https://doi.org/10.1016/j.isprsjprs.2010.09.001

Lefsky, M.A., Cohen, W.B., Acker, S.A., Parker, G.G., Spies, T.A., Harding, D., 1999. Lidar Remote Sensing of the Canopy Structure and Biophysical Properties of Douglas-Fir Western Hemlock Forests. Remote Sens. Environ. 70, 339-361.

Lu, D., Chen, Q., Wang, G., Liu, L., Li, G., Moran, E., 2016. A survey of remote sensing-based aboveground biomass estimation methods in forest ecosystems. Int. J. Digit. Earth 9, 63-105.

Mallat, S.G., 1989. A Theory for Multiresolution Signal Decomposition: The Wavelet Representation. IEEE Trans. Pattern Anal. Mach. Intell. https://doi.org/10.1109/34.192463

Marchi, N., Pirotti, F., Lingua, E., 2018. Airborne and Terrestrial Laser Scanning Data for the Assessment of Standing and Lying Deadwood: Current Situation and New Perspectives. Remote Sens. 10, 1356. https://doi.org/10.3390/rs10091356

Peregon, A., Yamagata, Y., 2013. The use of ALOS/PALSAR backscatter to estimate above-ground forest biomass: A case study in Western Siberia. Remote Sens. Environ. 137, 139-146. https://doi.org/10.1016/j.rse.2013.06.012

Pirotti, F., 2019. Open software and standards in the realm of laser scanning technology. Open Geospatial Data, Softw. Stand. 4, 14. https://doi.org/10.1186/s40965-019-0073-z

\section{Schmidt, H., 1977. DINAMICA DE UN BOSQUE VIRGEN DE ARAUCARIA - LENGA (Chile). Bosque. https://doi.org/10.4206/bosque.1977.v2n1-02}

Segura, M., Kanninen, M., 2005. Allometric models for tree volume and total aboveground biomass in a tropical humid forest in Costa Rica. Biotropica. https://doi.org/10.1111/j.17447429.2005.02027.x

Shimada, M., 2010. Ortho-Rectification and Slope Correction of SAR Data Using DEM and Its Accuracy Evaluation. IEEE J. Sel. Top. Appl. Earth Obs. Remote Sens. https://doi.org/10.1109/JSTARS.2010.2072984

Small, D., 2011. Flattening gamma: Radiometric terrain correction for SAR imagery. IEEE Trans. Geosci. Remote Sens. https://doi.org/10.1109/TGRS.2011.2120616

Steininger, M.K., 2000. Satellite estimation of tropical secondary forest above-ground biomass: Data from Brazil and Bolivi. Int. J. Remote Sens. 21, 1139-1157. https://doi.org/10.1080/014311600210119

Tonolli, S., Dalponte, M., Neteler, M., Rodeghiero, M., Vescovo, L., Gianelle, D., 2011. Remote Sensing of Environment Fusion of airborne LiDAR and satellite multispectral data for the estimation of timber volume in the Southern Alps. Remote Sens. Environ. 115, 2486-2498. https://doi.org/10.1016/j.rse.2011.05.009

Ulaby, F.T., Allen, C.T., Eger, G., Kanemasu, E., 1984. Relating the microwave backscattering coefficient to leaf area index. Remote Sens. Environ. https://doi.org/10.1016/00344257(84)90010-5

Vaglio Laurin, G., Pirotti, F., Callegari, M., Chen, Q., Cuozzo, G., Lingua, E., Notarnicola, C., Papale, D., 2016. Potential of ALOS2 and NDVI to Estimate Forest Above-Ground Biomass, and Comparison with Lidar-Derived Estimates. Remote Sens. 9 , 18. https://doi.org/10.3390/rs9010018

van der Meer, F.D., Bakker, W., Scholte, K., Skidmore, A.K., de Jong, S.M., Clevers, J.G.P.W., Epema, G.F., 2000. Vegetation indices, above ground biomass estimates and the red edge from MERIS. Int. Arch. Photogramm. Remote Sens.

Wang, G., Zhang, M., Gertner, G.Z., Oyana, T., McRoberts, R.E., Ge, H., 2011. Uncertainties of mapping aboveground forest carbon due to plot locations using national forest inventory plot and remotely sensed data. Scand. J. For. Res. https://doi.org/10.1080/02827581.2011.564204

Whitcher, B., 2019. waveslim: Basic Wavelet Routines for One, Two- And Three-Dimensional Signal Processing.

Wohlfart, C., Winkler, K., Wendleder, A., Roth, A., 2018. TerraSAR-X and Wetlands: A Review. Remote Sens. 10, 916.

Yáñez, L., Homolová, L., Malenovský, Z., Schaepman, M., 2008. Geometrical and structural parametrisation of forest canopy radiative transfer by measurements. Int. Arch. Photogramm. Remote Sens. Spat. Inf. Sci. 37 (Part B, 45-50. 